\title{
Effects of Petroselinum crispum and Coriandrum sativum on Oral Cadmium-induced
}

\section{Micronucleus Formation in Mice}

\author{
Huifeng ReN ${ }^{1}$, Huijuan JiA ${ }^{1,2^{*}}$, Haruka SuzukI ${ }^{1}$, Yusaku NAGAE ${ }^{1}$ and Hideaki ENDO ${ }^{1}$ \\ ${ }^{1}$ Department of Marine Science, Tokyo University of Marine Science and Technology (TUMST), Tokyo 108-8477, Japan \\ ${ }^{2}$ Corporate Sponsored Research Program "Food for Life” Organization for Interdisciplinary Research Projects, The University of Tokyo, \\ Tokyo 113-8654, Japan
}

Received August 20, 2012; Accepted December 3, 2012

This paper reports the effects of umbelliferous plants on Cd-induced micronucleus formation in Cdexposed mice. After ICR mice ( 7 w) were given free access to a $100 \mathrm{mg} / \mathrm{kg}$ Cd solution for 12 days, they were fed with a standard diet and a control diet supplemented with Petroselinum crispum (Pc) or Coriandrum sativum (Cs) for $\mathbf{7 0}$ days. Femoral bone marrow smears were prepared every 2 weeks, and micronucleus frequency was determined from the micronucleated polychromatic erythrocyte count. The micronucleus frequency obtained from the positive control group was approximately 2 -fold higher than that in the negative control group (No Cd administration) $(P<0.05)$. However, micronucleus frequencies in the Cs and Pc groups were decreased by $21-60 \%(P<0.05)$ compared to that of the positive control group. These results suggest that consumption of these two plants might inhibit genotoxicity and possibly even reduce the risk of aging and carcinogenesis induced by $\mathrm{Cd}$.

Keywords: Petroselinum crispum, Coriandrum sativum, cadmium, ICR mice, micronucleus frequency, genotoxicity

\section{Introduction}

Cadmium $(\mathrm{Cd})$ is a known genotoxic substance. The biological half-life of this harmful heavy metal has been estimated to be $12-50$ years, and long-term ingestion of Cd causes its accumulation in the body (Elinder et al., 1976; Sugita and Tsuchiya, 1995; Kjellström and Nordberg 1978). Chronic exposure to $\mathrm{Cd}$ may increase the risk of malignant neoplasms, chromosomal aberrations, and micronucleus induction (Jagetia and Adiga, 1994; Lin et al., 1994). Cadmium can induce carcinogenicity in humans (i http://monographs. iarc.fr/ENG/Monographs/vol58/mono58-7A.pdf), and the IARC classified $\mathrm{Cd}$ as a group 1 carcinogen in 1993.

Humans can be exposed to $\mathrm{Cd}$ via oral and nasal routes. The general public is exposed to $\mathrm{Cd}$ through the consumption of a variety of foodstuffs, such as crops grown in Cdcontaminated soil or fish obtained from Cd-contaminated rivers. Japan is a volcanic country with abounding sites for mining throughout the land area, thus leading to the production of a substantial amount of mining waste. Numerous

*To whom correspondence should be addressed.

E-mail: ginajhj77@yahoo.co.jp studies revealed that the level of $\mathrm{Cd}$ exposure among the Japanese population is higher than that in the surrounding Asian countries (Watanabe et al., 1985; Zhang et al., 1997; Ikeda et al., 1996; Zhang et al., 1998; Moon et al., 1998; Kikuchi et al., 2002; Ikeda et al., 1999).

According to the Ministry of Agriculture, Forestry and Fisheries (MAFF) report "Annual changes in daily intake of cadmium from daily meal" (ii http://www.maff.go.jp/j/ syouan/nouan/kome/k_cd/cyosa/pdf/cd-tds.pdf), the daily intake of $\mathrm{Cd}$ from 14 cultivars of plants decreased from 31.1 $\mu \mathrm{g} / \mathrm{person} /$ day in 1981 to $23.5 \mu \mathrm{g} /$ person/day in 2009 . These results are based on the survey conducted by the National Institute of Health Sciences $(1981$ - 2009) on the amount of pollutants consumed daily in food. This level of daily intake is equivalent to $44 \%$ of the provisional tolerable weekly intake of $\mathrm{Cd}(7 \mu \mathrm{g} / \mathrm{kg}$ weight/week), but it exceeds the tolerable weekly intake set by the Risk Assessment of the European Food Safety Authority ( $2.8 \mu \mathrm{g} / \mathrm{kg}$ weight/week). According to this report, the amounts of $\mathrm{Cd}$ ingested from three types of food, namely, rice, colored vegetables, and vegetables and seaweed, were $8.82,1.06$, and $2.46 \mu \mathrm{g} /$ person/ day, respectively. These levels are $46-55 \%$ lower than the 
levels reported in 1981. In contrast, the amount of Cd ingested from three other types of foods, seafood, meat and eggs, and processed food, were $6.41,0.45$, and $0.44 \mu \mathrm{g} /$ person/ day, respectively, which are $2.4-3.5$-fold higher than levels reported in 1981. Considering the toxicity and accumulative property of $\mathrm{Cd}$, it is desirable to minimize $\mathrm{Cd}$ accumulation in the body as much as possible to prevent detriments from Cd (Nomiyama, 2006).

Parsley (Petroselinum crispum, Pc) and coriander (Coriandrum sativum, Cs) are plants belonging to Umbelliferae, both of which are rich in functional ingredients such as vitamins, polyphenols, and minerals. Previous research showed the anti-oxidant and inhibitory effects of Pc and Cs against several well-known mutagens (Aga et al., 2001; Zhang et al., 2006; Ramadan and Moersel, 2006). In our previous studies, we administered freeze-dried Pc and Cs to several cultured fish with accumulated $\mathrm{Cd}$, and the results revealed that Pc and Cs accelerate Cd excretion (Ren et al., 2006; Ren et al., 2009; Jia et al., 2009; Jia et al., 2010). Few studies have investigated the effects of $\mathrm{Cd}$ accumulation in mice on chromosomal aberrations, which is an important indicator of genotoxicity. In this study, we administered Pc and Cs powder to Cd-exposed ICR mice and examined the effect of these plants on Cd-induced genotoxicity using the micronucleus test.

\section{Materials and Methods}

Preparation of $P c$ and $C s \quad$ Both Cs and Pc were purchased from Shizuoka Agricultural Cooperative Federation. After roots were cut off, they were vacuum freeze-dried at $-40^{\circ} \mathrm{C}$ for $48 \mathrm{~h}$, and then crushed to powder in a mixer. These materials were stored at $-20^{\circ} \mathrm{C}$ until use.

Experimental animals and diets ICR mice (male, 7 weeks old) used in the study were purchased from Japan SLC Inc. and bred at $25 \pm 2{ }^{\circ} \mathrm{C}$, with $60 \%$ humidity and a 12-h light-dark cycle. The CLEA Rodent Diet CE-2, purchased from CLEA Japan Co., Ltd., was used as the standard diet. The Pc- and Cs-containing experimental diets $(20 \%$ on a fresh weight basis) were prepared by Japan CLEA Co., Ltd.

After a 3-day acclimatization period, all the mice were divided into two groups: a negative control group $(\mathrm{n}=21)$ and an experimental group $(n=63)$. We administered the standard diet and tap water to the negative control group throughout this study. The experimental group mice were administered the standard diet with free access to $100 \mathrm{mg} /$ $\mathrm{kg}$ Cd solution for 12 days. Subsequently, the experimental group was further divided into three groups $(\mathrm{n}=21$ each): the positive control group, the Pc-administered group, and the Cs-administered group. The mice of these groups were administered the standard diet, Pc-containing diet, or Cs- containing diet for 70 days. All mice were given free access to tap water during this period. Water and diet were replaced daily, and body weights were measured every 14 days. This study was approved by the Institutional Animal Care and Use Committee of Tokyo University of Marine Science and Technology, and the animals were treated in accordance with their guidelines.

Micronucleus test and statistical analysis Bone marrow smears were prepared from the femur bone according to the conventional method (Schmid, 1973; Von Ledebur and Schmid, 1973). Marrow was collected from each group before $\mathrm{Cd}$ administration (day 0), after 12 days of $\mathrm{Cd}$ administration (day 13), and every 2 weeks after the start of Pc- or Cs-containing diet administration (days 27, 41, 55, 69 , and 83 ). One thousand polychromatic erythrocytes were observed under the microscope $(\times 1000)$ for each mouse, and the micronucleated polychromatic erythrocytes were counted to determine the micronucleus frequency $(\%)$. The average micronucleus frequency was calculated for each group using 3000 micronucleated polychromatic erythrocytes. Tukey's test and two-way ANOVA were used for data analysis. A $P$ value of $<0.05$ was considered statistically significant.

\section{Results}

Effects of $C d, P c$, and Cs on the growth of mice The average body weights of mice before $\mathrm{Cd}$ administration (day 0 ), after Cd administration (day 13), and every 14 days after the start of Cs or Pc administration are summarized in Fig. 1. At the start of breeding, the average weight was $34.3 \pm 0.8 \mathrm{~g}$. After 12 days, the body weight of the negative control group without Cd exposure increased to $41.4 \pm 0.5 \mathrm{~g}$ (day 13). In

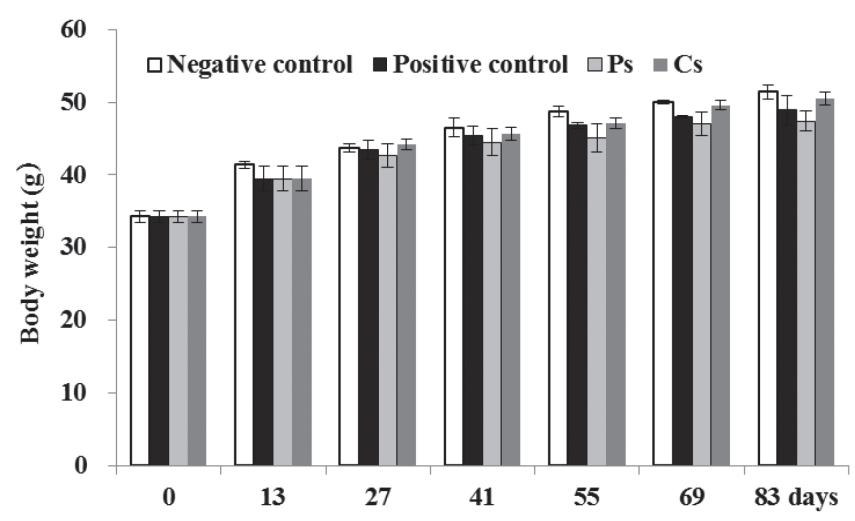

Fig. 1. Changes in body weight. The standard diet and tap water were given to the negative control group throughout the whole period. The ICR mice (male, 7 weeks old) in the positive control, Ps, and Cs groups were given the standard diet with free access to 100 $\mathrm{mg} / \mathrm{kg} \mathrm{Cd}$ solution for 12 days, and then were given the standard diet, Pc-containing diet (20\% of fresh weight), or Cs-containing diet ( $20 \%$ of fresh weight) for 70 days with free access to tap water during this period. Food and water consumption were measured every day, and body weights were measured every 2 weeks. 
Table 1. Changes in micronucleus frequencies in each group (\%).

\begin{tabular}{lccccccc}
\hline & 0 & 13 & 27 & 41 & 55 & 69 & 83 days \\
\hline Control groups & & & & & & \\
$\quad$ Negative control & $4.00 \pm 1.00$ & $4.67 \pm 0.58$ & $3.67 \pm 0.58$ & $3.67 \pm 0.58$ & $3.67 \pm 0.58$ & $3.33 \pm 1.56$ & $3.33 \pm 1.53$ \\
$\quad$ Positive control & $4.00 \pm 1.00$ & $9.33 \pm 2.08^{\#}$ & $11.33 \pm 1.15^{\#}$ & $10.00 \pm 1.73^{\#}$ & $11.00 \pm 2.08^{\#}$ & $12.33 \pm 1.53^{\#}$ & $11.68 \pm 2.31^{\#}$ \\
$\quad$ Increasing ratio (\%) & 0 & 100 & 209 & 172 & 200 & 270 & 251 \\
Experimental groups & & & & & & \\
$\quad$ Pc group & $4.00 \pm 1.00$ & $9.33 \pm 2.08$ & $9.00 \pm 2.65$ & $3.33 \pm 1.53^{*}$ & $4.33 \pm 1.53^{*}$ & $4.33 \pm 2.51^{*}$ & $4.67 \pm 1.52^{*}$ \\
Cs group & $4.00 \pm 1.00$ & $9.33 \pm 2.08$ & $8.67 \pm 1.53$ & $6.67 \pm 2.08$ & $7.67 \pm 2.08$ & $6.33 \pm 2.08^{*}$ & $5.33 \pm 0.58^{*}$ \\
\hline
\end{tabular}

Bone marrow smears were prepared before Cd administration (day 0), after 12 days of $\mathrm{Cd}$ administration (day 13), and every 2 weeks after the start of Pc- or Cs-containing diet administration (days 27, 41, 55, 69, and 83). The increasing ratio is the micronucleus frequency changed in the positive group to the frequency in the negative control group. ${ }^{\#} P<0.05$, positive control vs. negative control; $* P<0.05$, experimental group vs. positive control.

contrast, the body weight of the Cd-administered group was $39.7 \pm 1.7 \mathrm{~g}$, which was slightly but not significantly lower than that in the negative control group. Pc and Cs administration also had no effect on mouse weight compared with that observed in the negative control group. These data suggest that no effect of $\mathrm{Cd}, \mathrm{Pc}$, and $\mathrm{Cs}$ was observed on the growth of mice.

Micronucleus induction of $\mathrm{Cd}$ Frequencies of micronucleus induction in the negative and positive control groups are summarized in Table 1. The frequencies of micronucleus induction from day 0 to day 83 in the negative control group ranged from $3.33 \%$ to $4.67 \%$, indicating that the micronucleus frequencies did not change during the feeding period in untreated mice. On the contrary, the micronucleus frequency in the positive control group increased significantly from $4.00 \%$ before $\mathrm{Cd}$ administration (day 0 ) to $9.33 \%$ after 12 days of $\mathrm{Cd}$ administration (day 13). The micronucleus frequencies in the samples taken every 14 days were $10.00-$ $12.33 \%$, indicating that it remained elevated throughout this Cd-exposed period. The percentage increase was calculated as the micronucleus frequency induced by $\mathrm{Cd}$ administration relative to that of the negative control group. As shown in Table 1, the percentage increase changed from $100 \%$ on day 13 to $251 \%$ on day 83 , and the degree of the increase was correlated with the period.

Inhibitory effects of Pc and Cs on micronucleus induction Changes in the micronucleus frequency in the Pc and Cs administration groups are shown in Table 1. In the Pcadministered group, a micronucleus frequency of $9.00 \%$ was detected on day 27 , indicating almost no change resulting from Pc administration compared to the positive control group until 27 days. However, the micronucleus frequency significantly decreased to $3.33 \%$ on day $41(P<0.05)$, and on day 83 , the last day of the breeding period, it was $4.67 \%$, which was similar to that in the negative control group. The inhibition ratio, the micronucleus frequency changed in the
Pc-administered group to the frequency in the positive control group (Fig. 2), was $21-67 \%$ in the Pc-administered group.

In the Cs-administered group, the micronucleus frequency decreased from $9.33 \%$ on day 13 to $5.33 \%$ on day 83 (Table 1). Similarly, the inhibition ratio of micronucleus frequency as described above was $23-54 \%(P<0.05)$ in the Cs-administered group (Fig. 2). The inhibitory effects of Cs on micronucleus induction increased as the Cs feeding period increased. Excluding day 27, the inhibition ratio of micronucleus frequency in the Pc-administered group was significantly higher than that in the Cs-administered group for all time points.

\section{Discussion}

During the Cd-exposure period of our experiment, the mean body weight of the mice was $38 \mathrm{~g}$, and the average water consumption was $6 \mathrm{~mL}$. Accordingly, the amount of $\mathrm{Cd}$

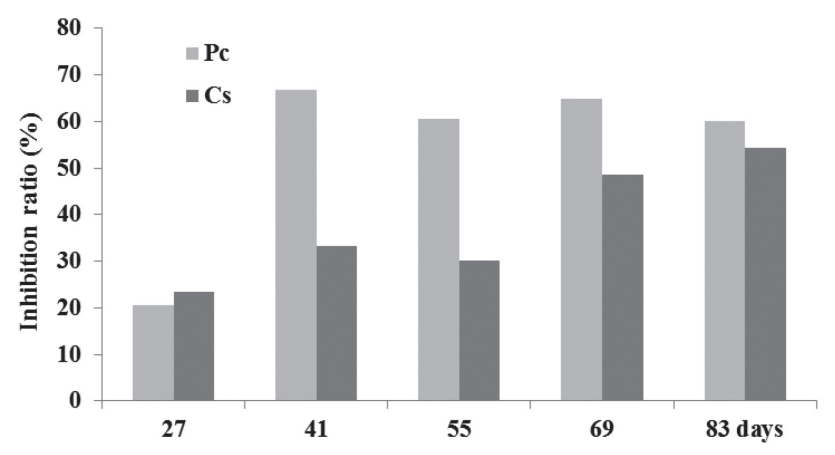

Fig. 2. Inhibitory effects of $\mathrm{Cs}$ and $\mathrm{Pc}$ on micronucleus induction. Bone marrow smears were prepared before $\mathrm{Cd}$ administration (day 0 ), after 12 days of $\mathrm{Cd}$ administration (day 13), and every 2 weeks after the start of Pc- or Cs-containing diet administration (days 27, $41,55,69$, and 83 ). The average micronucleus frequency (\%) was calculated for each group using 3000 micronucleated polychromatic erythrocytes. The inhibition ratio is the micronucleus frequency changed in the Pc-administered group to the frequency in the positive control group. 
ingested relative to body weight was $16 \mathrm{mg} / \mathrm{kg} /$ day. In addition, the mean intake of Pc and Cs was 3.73 and $3.64 \mathrm{~g} / \mathrm{kg} /$ day, respectively. The changes in body weight in the positive control group, Pc-administered group, and Cs-administered group were not statistically different from that in the negative control group. Food and water consumption was also the same in all groups at each time (data not shown). Thijssen et al. reported that the weight of C57BL/6 (aged $8-10$ weeks) mice exposed to $100 \mathrm{mg} \mathrm{CdCl} / 1$ was significantly different from the weight of the control group at 23 weeks (Thijssen, 2007). These results indicate that short-term chronic Cd exposure did not affect water and food consumption, nor did it inhibit growth. Neither Pc nor Cs administration had a statistically significant effect on body weight, indicating that the unique fragrance of the Pc- and Cs-containing diets did not alter the appetite of the mice.

The induction of chromosomal aberrations is one of the important indicators of genotoxicity. Micronuclei are caused by structural chromosomal abnormalities or mitotic abnormalities (Heddle and Carrano, 1977). The micronucleus test examines the mutagenicity of chemicals based on micronucleus formation in bone marrow cells (erythrocytes), which is useful for screening potential carcinogenicity of harmful chemicals. Karmakar et al. (1978) reported that intraperitoneal administration of $\mathrm{CdCl}_{2}(2.5 \mathrm{mg} / \mathrm{kg})$ in mice every other day for up to 15 days resulted in decreased glutathioneS-transferase (GST) and glutathione activities, increased frequencies of chromosomal aberrations and micronucleus formation, and a significant decrease in the mitotic index in bone marrow cells.

The genotoxicity of $\mathrm{Cd}$ is due to oxidative deterioration in which reactive oxygen species (ROS) such as hydrogen peroxide are formed, causing cell membrane damage and DNA strand breaks (Fotakis et al., 2005; Watjen and Beyersmann, 2004). Cells can normally defend themselves against ROS damage using anti-oxidant enzymes such as superoxide dismutase, catalase, glutathione peroxidase, glutathione reductase, and GST. Polyphenols, carotenoids, and flavonoids are known to be responsible for antioxidant activities, which can exert a stimulatory action on transcription and gene expression of certain antioxidant enzymes (Rordanz et al., 2002). According to our results, the addition of Pc or Cs reduced the Cd-induced frequencies of micronucleus formation and chromosome abnormalities by $21-67 \%$. The inhibitory effects of Pc were slightly stronger than those of Cs. As we did not measure the effect of each functional component in $\mathrm{Pc}$ or Cs, specific components with the strongest effects on micronucleus induction were not identified. However, numerous studies have indicated that compounds present in vegetables such as vitamin $C$, vitamin $A, \beta$-carotene, $\alpha$-carotene, polyphenols, peroxidase, and dietary fiber have anti-mutagenic effects. Many bioactive phytochemicals have been previously identified including flavonoids such as apiin and luteolin and carotenoids in Pc (Karimi, 2012; Daly et al., 2010), and catechol, salicylic acid, glycitin, pyrogallol, gentisic acid, protocatechiuic acid, quinic acid, caffeic acid, ferulic acid, gallic acid, and chlorogenic acid in Cs (Wangensteen et al., 2004; de Almeida Melo et al., 2005; Bajpai et al., 2005). Many of these are phenolic compounds that have been demonstrated as potential treatments for diverse physiological pathologies.

In addition, several in vivo studies have also shown that Cs or Pc intake increases the activity of antioxidant enzymes and restores the levels of thiobarbituric acid reactive substances, which are the products of lipid peroxidation (Aga et al., 2001; Nielsen et al., 1999; Sreelatha and Inbavalli, 2012; Sharma et al., 2010). Shimizu et al. examined the inhibitory effects of the methanol extracts of 121 species of green and yellow vegetables and fruits on the promotion phase of carcinogenesis. Fourteen of the extracts, including the Pc extract, inhibited the promotion phase by at least 70\% (Koshimizu, 1991). In addition, the acetone extract of Cs exhibited inhibitory effects on mutagenicity (Cortés-Eslava et al., 2001). Both Pc and Cs are umbelliferous plants, and their edible portions contain functional components with antioxidant or anti-mutagenic properties, such as a variety of vitamins and flavonoids. For instance, $100 \mathrm{~g}$ fresh Pc contains $7.40 \mathrm{mg}$ $\alpha$-carotene, $0.24 \mathrm{mg}$ vitamin B2, $0.22 \mu \mathrm{g}$ folic acid, 120.00 $\mathrm{mg}$ vitamin C, $3.30 \mathrm{mg} \alpha$-tocopherol, $7.50 \mathrm{mg}$ iron, 290.00 $\mathrm{mg}$ calcium, $3.60 \mathrm{mg}$ zinc, $630.00 \mathrm{mg}$ apigenin, $4.00 \mathrm{mg}$ luteolin, $10.01 \mathrm{mg}$ lutein, $1.00 \mathrm{mg}$ kaempferol, $8.08 \mathrm{mg}$ myricetin, and $1.00 \mathrm{mg}$ quercetin (MECSST, 2000; Macheix et al., 1990; iii http://www.nal.usda.gov/fnic/foodcomp/Data/Flav/ Flav02-1.pdf). According to a food polyphenol content pyramid created by Kanazawa et al., the polyphenol content in Pc is higher than that in Cs (iv http://scfdb.tokyo.jst.go.jp/pdf/2 0001150/2002/200011502002rr.pdf).

Based on these findings, we suggest that not a single component, but the interactions of vitamins, flavonoids, dietary fiber, and trace metal ions in these plants contribute to the inhibitory effects of $\mathrm{Pc}$ and $\mathrm{Cs}$ on the micronucleus frequency. Human carcinogenesis, aging, and genotoxicity may be inhibited by consuming these umbelliferous plants. For our future study, we plan to examine the effects of $\mathrm{Pc}$ and $\mathrm{Cs}$ on Cd absorption and other harmful heavy metals including $\mathrm{Hg}, \mathrm{Al}$, and other harmful substances such as $\mathrm{Pb}$, polychlorinated biphenyl, polycyclic aromatic hydrocarbon, pesticides, and antibiotics. 


\section{References}

Aga, M., Iwaki, K., Ueda, Y., Ushio, S., Masaki, N., Fukuda, S., Kimoto, T., Ikeda, M. and Kurimoto, M. (2001). Preventive effect of Coriandrum sativum (Chinese parsley) on localized lead deposition in ICR mice. J. Ethnopharmacol., 77, 203-208.

Bajpai, M., Mishra, A. and Prakash, D. (2005). Antioxidant and free radical scavenging activities of some leafy vegetables. Int. J. Food Sci. Nutr., 56, 473-481.

Cortés-Eslava, J., Gómez-Arroyo, S., Villalobos-Pietrini, R. and Espinosa-Aguirre, J.J. (2001). Metabolic activation of three arylamines and two organophosphorus insecticides by coriander (Coriandrum sativum) a common edible vegetable. Toxicol. Lett., 125, 39-49.

Daly, T., Jiwan, M.A., O'Brein, M. and Aherne, S.A. (2010). Carotenoid content of commonly consumed herbs and assessment of their bioaccessibility using an in vitro digestion model. Plant Foods Hum. Nutr., 65(2), 164-169.

de Almeida Melo, E., Filho, J.M. and Guerra, N.B. (2005). Characterization of antioxidant compounds in aqueous coriander extract (Coriandrum sativum L.). Lebensmittel-Wissenschaft \& Technologie, 38, 15-19.

Elinder, C.G., Kjellström, T., Friberg, L., Lind, B. and Linnman, L. (1976). Cadmium in kidney cortex, liver, and pancreas from Swedish autopsies. Arch. Environ. Health, 31, 292-302.

Fotakis, G., Cemeli, E., Anderson, D. and Timbrell, J.A. (2005). Cadmium chloride-induced DNA and lysosomal damage in a hepatoma cell line. Toxicol. In Vitro, 19, 481-489.

Heddle, J.A. and Carrano, A.V. (1977). The DNA content of micronuclei induced in mouse bone marrow by gamma-irradiation: evidence that micronuclei arise from acentric chromosomal fragments. Mutat. Res., 44, 63-69.

Ikeda, M., Zhang, Z.W., Higashikawa, K., Watanabe, T., Shimbo, S., Moon, C.S., Nakatsuka, H. and Matsuda-Inoguchi, N. (1999). Background exposure of general women populations in Japan to cadmium in the environment and possible health effects. Toxicol. Lett., 108, 161-166.

Ikeda, M., Zhang, Z.W., Moon, C.S., Imai, Y., Watanabe, T., Shimbo, S., Ma, W.C., Lee, C.C. and Guo, Y.L. (1996). Background exposure of general population to cadmium and lead in Tainan city, Taiwan. Arch. Environ. Contam. Toxicol., 30, 121-126.

Jagetia, G.C. and Adiga, S.K. (1994). Cadmium chloride induces dose-dependent increases in the frequency of micronuclei in mouse bone marrow. Mutat. Res., 306, 85-90.

Jia, H., Ren, H., Endo, H. and, Hayashi, T. (2010). Effect of cadmium binding form on rabbit aminolevulinate dehydratase in high molecular-weight fraction of rainbow trout liver. Fish. Sci., 76, 495-501.

Jia, H., Ren, H., Endo, H. and Hayashi, T. (2009). Effect of Chinese parsley Coriandrum sativum on cadmium binding to proteins from the liver and kidney of rainbow trout. Mar. Freshwater Be- hav. Physiol., 42, 187-199.

Karimi, M.H., Ebadi, P. and Amirghofran, Z. (2012). Parsley and immunomodulation. Expert Rev. Clin. Immunol., 8, 295-297.

Kikuchi, Y., Nomiyama, T., Kumagai, N., Uemura, T. and Omae, K. (2002). Cadmium concentration in current Japanese foods and beverages. J. Occup. Health, 44, 151-155.

Kjellström, T. and Nordberg, G.F. (1978). A kinetic model of cadmium metabolism in the human being. Environ. Res., 16, 248269.

Koshimizu, K. (1991). Dietary constituent that controls carcinogenesis promotion. Biosci. Biotechnol. Biochem., 29, 598-603.

Lin, R.H., Lee, C.H., Chen, W.K. and Lin-Shiau, S.Y. (1994). Studies on cytotoxic and genotoxic effects of cadmium nitrate and lead nitrate in chinese hamster ovary cells. Environ. Mol. Mutagen., 23, 143-149.

Macheix, J.J., Fleuriet, A. and Billot, J. (1990). Fruit Phenolics, CRC press, Boca Raton, FL.

MECSST, Ministry of Education, Culture, Sports, Science \& Technology in Japan, Standard Tables of Food Composition in Japan Fifth Revised Edition, National Printing Bureau, Tokyo, 2000.

Moon, C.S., Zhang, Z.W., Shimbo, S., Watanabe, T., Moon, D.H., Lee, C.U., Lee, B.K., Ahn, K.D., Lee, S.H. and Ikeda, M. (1998). Evaluation of urinary cadmium and lead as markers of background exposure of middle-aged women in Korea. Int. Arch. Occup. Environ. Health, 71, 251-256.

Nielsen, S.E., Young, J.F., Daneshvar, B., Lauridsen, S.T., Knuthsen, P., Sandström, B. and Dragsted, L.O. (1999). Effect of parsley (Petroselinum crispum) intake on urinary apigenin excretion, blood antioxidant enzymes and biomarkers for oxidative stress in human subjects. Br. J. Nutr., 81(6), 447-55.

Nomiyama, T. (2006). Health Effect of Environmental Cadmium Exposure - recent Reevaluation on Provisional Tolerable Weekly Intake on the Joint FAO/WHO Food Standards Programme. The Shinshu Medical Journal, 154, 175-182.

Ramadan, M.F. and Moersel, J.T. (2006). Screening of the antiradical action of vegetable oils. J. Food Compos. Anal., 19, 838-842.

Ren, H., Jia, H., Maita, M., Satoh, S., Endo, H. and Hayashi, T. (2009). Cadmium detoxification effect of Chinese parsley, Coriandrum sativum, in liver and kidney of rainbow trout, Onchorhynchus mykiss. Fish. Sci., 75, 731-741.

Ren, H., Jia, H., Kim, S., Maita, M., Sato, S., Yasui, M., Endo, H. and Hayashi, T. (2006). Effects of Chinese parsley Coriandrum sativum and chitosan on inhibiting the accumulation of cadmium in cultured rainbow trout Oncorhynchus mykiss. Fish. Sci., 72, 263-269.

Rohrdanz, E., Ohler, S., Tran-Thi, Q.H. and Kahl, R. (2002). The phytoestrogen daidzein affects the antioxidant enzyme system of rat hepatoma H4IIE cells. J. Nutr., 132, 370-375.

Schmid, W. (1973). Chemical mutagen testing in vivo somatic mammalian cells. Agents Actions, 3, 77-85. 
Sharma, V., Kansal, L. and Sharma, A. (2010). Prophylactic efficacy of Coriandrum sativum (Coriander) on testis of lead-exposed mice. Biol. Trace Elem. Res., 136, 337-354.

Sreelatha, S. and Inbavalli, R. (2012). Antioxidant, antihyperglycemic, and antihyperlipidemic effects of Coriandrum sativum leaf and stem in alloxan-induced diabetic rats. J. Food Sci., 77, T11923.

Sugita, M. and Tsuchiya, K. (1995). Estimation of variation among individuals of biological half-time of cadmium calculated from accumulation data. Environ. Res., 68, 31-37.

Thijssen, S., Maringwa, J., Faes, C., Lambrichts, I. and Van Kerkhove, E. (2007). Chronic exposure of mice to environmentally relevant, low doses of cadmium leads to early renal damage, not predicted by blood or urine cadmium levels. Toxicology, 229, 145-56.

Von Ledebur, M. and Schmid, W. (1973). The micronucleus test. Methodology aspects. Mutat. Res., 19, 109-117.

Wangensteen, H., Samuelsen, A.B. and Malterud, K.E. (2004). Antioxidant activity in extracts from coriander. Food Chem. Toxicol., 88, 293-297.

Watanabe, I., Koizumi, A., Fujita, H., Kumai, M. and Ikeda, M. (1985). Dietary cadmium intakes of farmers in nonpolluted areas in Japan and the relation with blood cadmium levels. Environ. Res., 37, 33-43.

Watjen, W. and Beyersmann, D. (2004). Cadmium-induced apoptosis in C6 glioma cells: influence of oxidative stress. Biometals, 17, 65-78.

Zhang, H., Chen, F., Wang, X. and Yao, H. (2006). Evaluation of antioxidant activity of parsley (Petroselinum crispum) essential oil and identification of its antioxidant constituents. Food Res. Int., 39, 833-839.

Zhang, Z. W., Moon, C.S., Watanabe, T., Shimbo, S., He, F.S., Wu, Y.Q., Zhou, S.F., Su, D.M., Qu, J.B. and Ikeda, M. (1997). Background exposure of urban populations to lead and cadmium: comparison between China and Japan. Int. Arch. Occup. Environ. Health, 69, 273-281.

Zhang, Z.W., Subida, R.D., Agetano, M.G., Nakatsuka, H., Inoguchi, N., Watanabe, T., Shimbo, S., Higashikawa, K. and Ikeda, M. (1998). Non-occupational exposure of adult women in Manila, the Philippines, to lead and cadmium. Sci. Total Environ., 215, 157-165.

\section{URL Cited}

i) IARC, IARC Monographs on the Evaluation of Carcinogenic Risks to Humans. http://monographs.iarc.fr/ENG/Monographs/ vol58/mono58-7A.pdf (Jan. 5, 2010)

ii) MAFF, Ministry of Agriculture, Forestry \& Fisheries, http:// www.maff.go.jp/j/syouan/nouan/kome/k_cd/cyosa/pdf/cd-tds.pdf (Apr. 12, 2011)

iii) USDA database for the Flavonoid Content of Selected Food, http://www.nal.usda.gov/fnic/foodcomp/Data/Flav/Flav02-1.pdf (May 5, 2010)

iv) MECSST, Ministry of Education, Culture, Sports, Science \& Technology in Japan, http://scfdb.tokyo.jst.go.jp/pdf/20001150/2 002/200011502002rr.pdf (Nov. 12, 2010) 